\title{
WESTINDISCHE PREDIKANTEN
}

DOOR

S. KALFF

I

Hetgeen de kroniekschrijvers over de predikanten in Westindië opgeteekend hebben, mag als eene bijdrage beschouwd worden tot de kennis van de koloniale toestanden in de 17de en 18de eeuw en laat eenig licht vallen op personen en zaken, welke vaak sprekend en kenmerkend, ofschoon geenszins voorbeeldig zijn te noemen.

Echter is de geschiedenis inzonderheid van de Hervormde kerk onvolledig bekend geworden, mede door den brand te Paramaribo van het jaar 1821, waarbij de kerk der Hervormden door het vuur verwoest werd en tal van belangrijke bescheiden en archivalia verloren gingen. De wedergade van zulke werken als Hofstede's Oostindische Kerkzaken, v. Troostenburg de Bruyn's Herv. Kerk in Ned. Oostindië en Biographisch Woordenboek van O. I. predikanten is voor Westindië niet aan te wijzen, en het blijft de vraag of dit hiaat ooit aangevuld zal worden.

De opkomst der Herv. kerk in Suriname was schamel genoeg; er was eene kleine gemeente, maar geen kerkgebouw, en in tegenstelling met Batavia, waar wel eens tien predikanten een werkkring vonden, was Paramaribo de standplaats van slechts een enkelen leeraar, aan wien eerst later een ambtgenoot als tweede predikant werd toegevoegd. Trouwens, volgens de opgave bij Hartsinck was Paramaribo in 1684 nog slechts een vlek van 27 of 28 huizen, waarbij een bedenkelijk aantal herbergen en kroegen. Als de eerste predikant stond te boek ds. Johannes Basseliers ${ }^{1}$ ), ook voorkomende onder de namen Baselier en

1) Zie over Baseliers „Stemmen des tijds, maandschrift voor Christendom 
Baselius, die in 1668 met de vloot van admiraal Crynssen in de kolonie kwam. Hij was de zoon van een gezeten burger te Middelburg, van beroep ijzerhandelaar, studeerde te Utrecht in de theologie en werd na den vrede van Breda in 1667, waarbij Suriname aan Nederland werd toegewezen, door de classis van Walcheren uitgezonden. Hij was ruim 18 jaren in de kolonie werkzaam; in 1689 nam zijne betrekking tot het wingewest een einde. Hij kwam ook in wereldlijke zaken genoegzaam naar den voorgrond om verkozen te worden tot lid van het Hof van Politie, welke benoeming hij echter niet aannam. Over de regeling zijner geldelijke aangelegenheden had hij alleszins reden zich te beklagen, want een jaar na zijne komst waren zijne overtochtskosten hem nog niet ten volle uitbetaald, en in 1676 had hij niet minder dan 8 jaren traktement te goed. Het spreekwoord dat wie het altaar bedient, moet van het altaar leven, scheen destijds voor de kolonie als niet geschreven te zijn.

Als de eerste diaken der Herv. gemeente fungeerde in 1669 Nicolaas Combé. Als kerk diende een gedeelte van het gebouw op het Kerkplein, dat tevens de bestemming van raadhuis en gasthuis had. Nog in 1744 werden de godsdienstoefeningen gehouden op de bovenzaal van het Hof van Politie, en het duurde tot 29 Mei 1817 alvorens te Paramaribo de eerste Herv. kerk kon worden ingewijd. De vereeniging van kerk en raadhuis in één gebouw werd trouwens ook in andere koloniën aangetroffen; te Batavia b.v., waar het stoffelijk overschot van Jan Pietersz. Coen in het Stadhuis ter aarde werd besteld, en eerst na de voltooiing van de Hollandsche of Kruiskerk derwaarts werd overgebracht. Ook in Suriname bestond dit uit het vaderland overgenomen gebruik om notabele personen in de gewijde aarde eener kerk te begraven.

Met het optreden van den gouverneur Cornelis van Aerssen van Sommelsdijck in 1683 kwam er eene opleving in de kerkelijke toestanden in de kolonie. Ofschoon in de gedenkschriften van den huisonderwijzer Jean Rou diens

en Cultuur”. October 1919: „Oud-hollandsche Zending in Suriname”, door Dr. A. A. van Schelven. 
beeld in een ongunstig licht verschijnt, zoo had hij toch volgens den geschiedschrijver Hartsinck ,eene zonderlinge (bijzondere) liefde voor den godsdienst, achting voor de godvreezenden en iever om hen te beschermen en te begunstigen". Met hem waren vele Fransche refugiés in Suriname gekomen, die er weldra eene eigen gemeente stichtten, terwijl hij ook de Labadisten steunde, die zich in 1684 op de plantage „La Providence” vestigden, en voor eene kerk in de Commewyne zorgde. Vóór 1682 stond de oudste Hervormde kerk aldaar, onder de hoede van ds. A. Backer, op den hoek Cales, d.i. den hoek van de Commewyne en de Casewinica, tegenover de Bottelkreek. Sommelsdyck deed eene kerk verrijzen bij het fort, aan de samenvloeiing van Commewijne en Cottica, welke in 1688 werd ingewijd door ds. Antonius Ketelaar. De gemeente Commewyne bestond gedurende 69 jaren; na 1757 werden er geene godsdienstoefeningen meer gehouden. De kerk was bouwvallig geworden en de middelen tot herstel ontbraken; ze werd in 't eind gesloopt. 't Laatst werd, in 1757, P. C. Johanzon tot predikant beroepen, doch dit beroep was provisioneel en in 't volgend jaar werd hij geplaatst bij de gemeente te Perica en Cottica ${ }^{1}$ ).

Deze laatste bezat in 1691 een eigen leeraar in den persoon van ds. Paules Kley, doch verkreeg eerst in 1721 een eigen kerk, welke gebouwd werd op een terrein van de plantage „Hulshof”, aan de Cottica-rivier, en ingewijd door ds. Henricus Entrop. Onder de predikanten bij deze gemeente ${ }^{1}$ ) onderscheidde zich door ijver en werkzaamheid ds. Emanuel Vieira, een bekeerde Israeliet, die in 1758 als buitengewoon predikant naar Paramaribo werd beroepen. Daarentegen werden twee anderen, Jan Martin Kleyn en Johan Willem Kals) ter zake van hun slecht gedrag en onstichtelijken levenswandel door het Hof van Politie uit de kolonie gezet.

Deze laatste, een voormalige Jezuï, had zich in 1726 te Utrecht als student in de theologie laten inschrijven, had

$\left.{ }^{1}\right)$ Lijst der predikanten het tijdschrift „West-Indië” 1854, C. v. Schaick. Bijdrage tot de gesch. d. Herv. Kerk in Suriname. 
daar het proponents-examen afgelegd en was in 1730 als predikant naar Suriname vertrokken, waar hij ongeveer twee jaren doorbracht.

't Waren voor hem jaren van tegenspoed, van onrust en aanvechting; eensdeels, naar de biograaf (v. Schelven) ${ }^{1}$ ) getuigt, , ,door het onvreedzame leven dat er tusschen hem en zijne vrouw, Anna Twisker, bestaan heeft, anderzijds door de bejegening van de zijde der koloniale autoriteiten en predikanten. Kals toch ging in menig opzicht te keer tegen dier mannen materialisme, machtswellust en verachting van de kleurlingen, die de 18de eeuwsche Surinaamsche maatschappij ontsierden". Ten gevolge van die vijandige verhouding met zijne omgeving werd hem ter hoofdplaats de grond te heet onder de voeten en verwisselde hij zijne standplaats aldaar met die in de meer afgelegen gemeenten Cottica en Perica, waar hij de nieuwgebouwde kerk inwijdde. Doch de moeilijkheden hielden daarmee niet op; ook daar geraakte hij in doornige kwesties. Door zijne tegenstanders werd hij aangeduid als ,een persoon van een onrustig en querelleus humeur, die zich noch aan wereldlijke, noch aan geestelijke regten en vermaningen wilde onderwerpen, maar zich halstarrig meerder en meerder in onrusten inwikkelde". Men bracht het zoo ver dat eerst voor een half jaar de "harde censuur" over hem werd uitgesproken, en in 1733 zijne verbanning (verzending) naar het moederland.

In Nederland verkreeg hij de genoegdoening, dat de classis Amsterdam zijne afzetting niet rechtmatig oordeelde. Doch dit bracht hem voorshands niet verder; maatregelen om hem in zijn werkkring in Suriname te herstellen werden niet genomen. In 1737 aanvaardde hij toen een beroep naar Stevensweerd (Stephenswaard in de classis Nijmegen), doch werd ongeveer vier jaren later ook daar geschorst; d.i. hij legde zijn ambt neer „om een onregtveerdige sententie te ontgaan". Van Amsterdam, waar hij eenigen tijd in zijn onderhoud voorzag door lessen te

1) „De Westindische Gids”, 4e jg. (1922) blz. 65-90: „Suriname in de $18 \mathrm{e}$ eeuw. (Ervaringen en idealen van Ds. Joa. Guil. Kals)", door Prof. Dr. A. A. van Schelven. 
geven, trok hij naar Leiden, welke stad hij weer verlaten moest door de ruchtbaarheid van eene liaison met zijne ook niet onbesprokene - dienstbode. Hij ging daarop naar Engeland, waar 't hem gelukte hooge beschermers te vinden, en eene betrekking als ,geadmitteerd onderwijzer in de oostersche talen" aan de universiteit te Oxford. Daar schreef hij zijn werk Grammatica Hebraeo-harmonica, doch dewijl hij dit in Engeland, waar het lettermateriaal ontbrak, niet gedrukt kon krijgen, verhuisde hij naar Bremen, waar hij begin 1754 eenigen tijd als leeraar aan het gymnasium fungeerde. Ook daar bleken de middelen om zijn boek te drukken niet voorhanden, waarom hij in 't laatst van hetzelfde jaar naar Amsterdam vertrok. Zijne pogingen om op nieuw naar Suriname te worden uitgezonden, mislukten; bewindhebbers wilden zelfs de opdracht van een zijner werken niet aanvaarden, noch op de gepubliceerde lijsten van Surinaamsche predikanten zijn naam vermelden. Blijkbaar stond hij op de ingekomen rapporten als het zwarte schaap onder de kudde te boek; en hetgeen er na zijn terugkeer met hem te Stevensweerd en Leiden was voorgevallen, was weinig geschikt om hem te rehabiliteeren.

Doch zeker vormde hij hierin eene uitzondering op de predikanten van zijn tijd, dat hij eene ongewone kennis van oostersche talen bezat, en tegen maatschappelijke euvels den strijd durfde aan te binden. Zijne werken, waar in hij te velde trok tegen het ,,verzuym van de Bekeringe der Heydenen" en tegen ,de bedorvene zeden der Voorgangeren" zouden er van getuigen. Zijne vroegere gemeente van Perica en Cottica werd in 1797 opgeheven, nadat haar laatste predikant J. C. de Cros naar Paramaribo was vertrokken. Ze had ruim een eeuw bestaan; er bleven daarvan geene sporen over behalve de ruïne aan de Cottica en een paar zilveren Avondmaalsbekers.

Veel korter bestond de gemeente te Thorarika, ook Santo Bridges ${ }^{1}$ ) genaamd, vroeger het hoofdkwartier der

1) Zie „Guiana Diocesan Magazine and Diocesan Garette for Church and Colony”, May 1919: „The Church of England in Surinam”, by Fred. Oudschans Dentz. 
Engelschen. De plaats telde een honderdtal huizen en een kapel; de gemeente, waar Bernhart Ter Maath als predikant werkzaam was, leidde slechts een paar jaren een zelfstandig bestaan en werd in 1.700 vereenigd met de gemeente te Paramaribo. Van latere dagteekening, nl. van het jaar 1845, was de gemeente aan de Saramacca, waar de landverhuizers onder leiding van de predikanten Coupijn en v. d. Brandhoff zich op den post Groningen hadden gevestigd. Toen deze kolonie werd opgeheven, hield ook de gemeente op te bestaan. Te Nickerie werden de godsdienstoefeningen gehouden in een houten gebouw, 't welk de plaats innam van de vroegere kerk te Nieuw Rotterdam. Vóór het jaar 1823 werd door den predikant van Paramaribo in de geestelijke behoeften der bevolking voorzien, doch in dat jaar werd voor dit doel de zendeling F. A. Wix uit Nederland gezonden. In 1855 werden voor 't eerst ouderlingen en diakenen voor deze gemeente benoemd door den kerkeraad der Herv. gemeente te Paramaribo, en drie jaren later vormde zij zich tot eene zelfstandige gemeente, buiten verband met die ter hoofdplaats.

Er bestond aldaar een conventus deputatorum, een kerkelijk college ingesteld onder het bestuur van den gouverneur Scharphuysen, dat eenmaal 's jaars eene vergadering hield ter bespreking van de zaken en belangen der kerk, en de behoeften der gemeenten in de kolonie. In deze vergadering hadden zitting twee leden van het Hof van Politie in de kwaliteit van commissaris politiek, uit hetzelfde beginsel waarom zulke gouvernements dwarskijkers ook in Oostindië bij den kerkeraad te Batavia, een oog in 't zeil hielden. De regeering wilde toezicht hebben op de "gedoentens" der geestelijke heeren, en zich overtuigen dat zij zich uitsluitend met kerkelijke belangen bezig hielden. De overheid zag in de predikanten uitsluitend personen, welke door bewindhebbers der Compagnie werden aangesteld en betaald, terwijl de predikanten het beginsel handhaafden dat de Kerk hare rechten had en de regeering zich niet behoorde te bemoeien met zaken, die van zuiver kerkelijken aard waren. Zelfs wa- 
ren er, die geen dienaren van de Comp. wilden heeten, maar alleen dienaren van Jezus Christus. (Bij wien ze dan hun traktement moesten halen, dit werd wijselijk in het midden gelaten).

In deze vergadering te Paramaribo kon het vaak heet toegaan, zoo door de krakeelen van de predikanten onderling als met de kerkeraden en het Hof van Politie. Men zag er soms zulke ergerlijke tooneelen, dat de commissarissen politiek zich genoopt zagen de vergadering op te heffen. Gedurende de hevige debatten kwam maar al te vaak aan het licht de waarheid van de bijbelsche uitspraak: „Die zijnen mond bewaart, behoudt zijne ziel; maar voor hem is verstoring, die zijne lippen wijd open doet" $\left.{ }^{1}\right)$. De Notulen van het Hof van Politie en de Journalen der gouverneurs gewagen herhaaldelijk van deze kerkelijke krakeelen. In een brief van 1749 door de classis van Amsterdam, waaronder Suriname kerkelijk ressorteerde, tot het conventus deputatorum gericht, werd de droefheid der vergadering kenbaar gemaakt „over de zware twisten, ja droevige oneenigheden, die zoover gingen dat de eene dienstknecht des Heeren den andere wel eens openlijk hoonde, schold en liefdeloos behandelde, terwijl $\mathrm{HH}$. predikanten zich niet ontzagen om door onbetamelijke uitdrukkingen enz. de hooge regeering te beleedigen". In een brief van 1750 door de classis tot gouverneur en raden gericht, werd verzocht den voornaamsten woelgeest, den Franschen predikant Duvoisin, als een ontaarden zoon tot rede en een betamelijk gedrag te brengen. Onder den gouverneur Mauricius trof men het ongelukkig met zekeren ds. Hoevenaar, die met recht een wargeest was; bij de minste tegenspraak geraakte hij in drift, rekende zich in zijne eer beleedigd en dreigde den beleediger met degen of pistool tot zwijgen te brengen na korten tijd werd hij volslagen waanzinnig ${ }^{2}$ ).

Het behoorde tot de instructie der predikanten, dat zij het licht van het Evangelie zouden verspreiden onder de „blinde heydenen", in dit geval de negerslaven der plan-

1) Spreuken XIII. 3.

2) Wolbers. Gesch. v. Suriname. bl. 196. 
tages, doch van hun bekeeringswerk zag men slechts poovere uitkomsten. Hetgeen er in dit opzicht tot stand werd gebracht, ging veelal uit van de paters der R. K. missie en van de Hernhutters. 'n Enkele maal slechts werd er een zieltje gewonnen voor de „ware gereformeerde religie", zooals in 1747, toen de Societeitsneger Benjamin zijne geloofsbelijdenis aflegde" met groote deftigheid, tot verbazing der aanwezenden". Hij werd daarop tot lidmaat der Herv. kerk aangenomen en gedoopt onder den naam van Jan Jacob van Paramaribo. Later werden nog een paar andere aangenomen; doch ten aanzien van een derde werd door ds. de Ronde, die hem in den christelijken godsdienst onderwees, bij den fiskaal de klacht ingebracht dat deze kandidaat-christen door zijn meester, den jood Machielse, werd mishandeld juist omdat hij christen wilde worden. In 1749 werd door den burger Picorna vrijlating verzocht voor zijne slavin Elisabeth met hare drie reeds gedoopte kinderen, hetgeen hem werd toegestaan. Doch andere burgers ondervonden van den kant der predikanten soms tegenwerking in plaats van medewerking, wanneer zij de kinderen, bij eene slavin ,geprocreërt”, in de christelijke leer wilden opvoeden. Zoo schreef kapt. J. G. Stedman in zijne Reize in de binnenlanden van Suriname over den predikant Suiderhans te Paramaribo, zoon van een grofsmid, dat deze weigerde om in de christelijke religie te onderwijzen het kind door Stedman bij de mulattin Johanna gewonnen. De predikant grondde deze weigering op het feit, dat Stedman de kolonie ging verlaten, derhalve niet in staat zou zijn om voor eene christelijke opvoeding van zijn zoon zorg te dragen. Het antwoord dat de knaap twee wakkere voogden had, welke die zorg op zich hadden genomen, kon aan zijn besluit niets veranderen; hij was voor alle vertoogen ,zoo doof als zijns vaders aanbeeld en waarachtig zoo ledig als zijns vaders blaasbalg". De schrijver vervolgde deze mededeeling met de regels:

„Eindelijk wierd ik zijne dweepzugtige onbeschoftheid moede en zwoer dat ik den jongen liever als een heiden zoude zien sterven dan hem door zulk een domkop tot het 
Christendom te laten brengen, en daarmede gong ik henen".

Dezelfde auteur gewaagde van het concubinaat, aan hetwelk zulke kinderen het aanzijn dankten, als van eene gevestigde instelling, welke tot de zeden des lands behoorde. Zoowel mulattinnen als negerinnen en Indiaansche vrouwen werden als bijzit genomen; zelfs van den gouverneur Sommelsdyck wiens vrouw in Nederland was achtergebleven, werd bericht dat hij met eene vrouw van de laatste soort zulk eene ongewijde verbintenis had gesloten. Het geval was onder de gouverneurs ook niet eenig; de Indische landvoogd baron G. W. van Imhoff, wiens vrouw in 1744 was gestorven, verwekte vier kinderen bij eene Bonische slavin, gedoopt onder den naam van Helena Pieters, en liet die kinderen legitimeeren. Stedman gaf te verstaan dat ook de ambtgenooten van ds Suiderhans van dit gebruik niet afkeerig waren, schrijvende:

„Alle schatten zij zig gelukkig met eenen Europeaan te leeven en zij dienen hem inderdaad ook bijna altoos met de grootste liefde en trouw, waarmede zij niet weinig tot verwijt verstrekken aan de ontelbare schoonen, die zig niet ontzien heiliger en plegtiger banden te schenden. Ook wordt dit gebruik aldaar zoo weinig gelaakt dat, zoo lang het meisjen den man, die het kiest, getrouw blijft haare vrienden en nabestaanden, welke dit als een wettig huwelijk beschouwen, haar steeds achten en ondersteunen. Geestelijke persoonen zelve ontzien zig niet deeze gewoonte te volgen".

De gouverneur Jan Jacob Mauricius, die een kerksch en godsdienstig man was, gaf zich veel moeite om het onderricht in de christelijke leer onder de slaven te bevorderen. Hij was trouwens gehouden de instructie voor de predikanten te doen naleven, welke voorschreef ,dat alle devoiren bij haar aangewent zullen werden omme de Portugeese, Spanjaarden ende haar kinderen te onderweyse in de fondamenten van de Christelycke Religie, alsmede de swarte ende Indianen". Doch hij stuitte bij zijne pogingen in die richting op den tegenstand van het Hof van 
Politie, waarvan de leden alle slavenhouders waren en die het eene bedenkelijke zaak achtten den slaaf zulke begrippen bij te brengen. Zij betrachtten op hunne wijs ten aanzien van den zwarten dienstbare het woord van den apostel, ,dat hij niet wijs boven hetgeen men behoort wijs te zijn, maar dat hij wijs zij tot matigheid". $\left.{ }^{1}\right)$ In 1751 beklaagde Mauricius zich bij bewindhebbers dat zijn streven voor de evangelisatie onder de slaven vruchteloos was geweest, en ook zijne bemoeienis ter zake bij de predikanten, waarbij hij de snijdende opmerking voegde dat een voornaam beletsel was ,het quaad exempel dat de meeste meesters aan hunne slaven gaven, zoodat de bekeering der zoogenaamde Christenen in de kolonie diende vooraf te gaan eer men van de bekeering der Heidenen iets hoopen mogt".

Ook voor de verkondiging van het evangelie onder de militairen gaven de predikanten zich weinig moeite. Ten einde op Zon- en feestdagen een voorganger te vinden bij het gebed en het voorlezen eener predikatie in het fort, moest men zijn toevlucht nemen tot een geschikt soldaat, zekeren Jan Ark, die daarvoor $f 15$ 's maands en dubbel rantsoen bekwam. Dezelfde deed ook dienst als ziekentrooster, bij gelegenheid dat twee veroordeelde deserteurs op den dood moesten voorbereid worden. 't Een en ander behoorde tot de besognes van den predikant. Daarentegen toonden deze eerwaarde broederen zich naijverig genoeg, wanneer 't hun toescheen dat hunne belangen bedreigd werden. Zoo kantten zij zich langen tijd tegen de vestiging eener Luthersche gemeente te Paramaribo, en namen tegenover de Hernhutters, die zooveel beter dan zij hunne geestelijke plichten betrachtten, eene wantrouwende houding aan. 't Was op hun aandrijven dat het Hof van Politie aan deze broeders verbood openlijke godsdienstoefeningen te houden, of ook toehoorders bij den huiselijken dienst toe te laten. In het conventus deputatorum van 1749 werd ,over de Hernhutteren gevoelens gedelibereerd en besloten steeds tegen dezelve te blijven waken".

1) Romeinen XII. 3. 
Ten einde in het gebrek aan predikanten te voorzien en in de gestadige vacatures bij vertrek of overlijden, werden wel eens plannen gemaakt, maar niet uitgevoerd. Men bracht het in dit opzicht niet zoo ver als in Oostindië, waar eenige proponenten en predikanten konden optreden, die afkomstig waren van de Leidsche kweekschool van prof. Walaeus; en waar te Batavia een seminarie voor de opleiding van Indische predikanten werd gevestigd (welke instelling echter slechts een tiental jaren bestond). Bewindhebbers van de W. I. Comp. hadden in de predikantsplaatsen te voorzien, doch waren daartoe niet altijd bij machte, zoo min als dit het geval was bij de $\mathrm{O}$. I. Comp. Art. 28 van het octrooi bepaalde dat zij moesten zorgen", dat de coloniers ten allen tijde zijn voorzien van een of meer Bedienaers des Goddelijken woorts, na dat de gelegentheydt van de colonie het zoude moghen komen te vereysschen, ten eynde de coloniers en de verdere opgezetenen aldaer in de vreeze des Heeren ende de leere der zaligheyt geleydt ende onderwesen mogen werden, mitsgaders tot het gebruyck der Heylige Sacramenten bequame occasie hebben, zullende de voornoemde Predikanten niet bij de voorz. compagnie, maar bij de coloniers en opgezetenen zelve onderhouden werden uyt een middel ofte fonds, dat den gemelten Gouverneur en de Raden daertoe op approbatie van de Bewindhebberen zullen mogen ordonneren te heffen".

Doch de kandidaten voor den dienst in Westindië waren vaak even moeilijk te vinden als voor dien in Oostindië, de gevaren en risico's van de zeereis, vooral in tijd van oorlog, schrikten vele af, evenals de gevaren van het klimaat en de inheemsche ziekten. Bij de gemeenten aan de Commewyne, Perica en Cottica, was de sterfte onder de predikanten inderdaad belangrijk geweest. Ook de stoffelijke voordeelen der betrekking waren weinig uitlokkend, en het voorbeeld van dien eersten predikant, Joh. Basseliers, die 8 jaren salaris te vorderen had, eene waarschuwing. (In Oostindië lieten speculatieve Comp. dienaren hun salaris niet zelden over de laatste jaren van hun diensttijd oploopen ten einde het zich na hunne repa- 
trieering in 't vaderland te laten uitbetalen). Om eenigszins in het voortdurend te kort aan predikanten te voorzien, waardoor ook in de oudere gemeenten hun plaats vaak jaren lang onbezet bleef, deed ds. Vieira het voorstel om, boven het gewone aantal predikanten, twee of meer proponenten in Nederland aan te vragen. Voorts om in het weeshuis te Paramaribo of op de scholen om te zien naar kinderen, bij welke men ,een snedig verstand, goed begrip en leerlust" bespeurde, ten einde hen ter opleiding naar Holland te zenden. Zij zouden zich na volbrachte studiën, moeten verbinden om naar Suriname terug te keeren, waartoe zij des te eerder geneigd zouden zijn dewijl zij daar hunne bloedverwanten en betrekkingen hadden. Wellicht zou men in zulke voedsterlingen eener vaderlandsche universiteit ook de personen vinden geschikt om als lectors of preceptors op te treden bij instellingen van kunst of wetenschap. Doch deze plannen namen nimmer een vasten vorm aan, veel minder kwamen ze tot een begin van uitvoering. 't Bleef bij discussiën, in eene gemeente van lauwe Laodiceërs hadden die plannen geen toekomst en een enkele zeloot gelijk ds. Vieira was niet bij machte om de bakens te verzetten.

De predikanten der Herv. gemeente, die zoozeer geijverd hadden tegen de oprichting van een Luthersch kerkgenootschap, en daarna ook het denkbeeld van eene fusie van beide gezindten hadden verworpen, kwamen wel in eene scheeve positie toen de brand van het jaar 1821 hun kerk had verwoest en zij genoodzaakt waren om bij de Lutherschen onderdak te komen. Die kerk was op 29 Mei 1814 ingewijd en voorzien met een uit Engeland ontboden orgel; alles, ook het archief, werd een prooi der vlammen. Maar in 1832 verbrandde ook de Luthersche kerk, en waren beide gemeenten onbehuisd. In 't volgend jaar werd toen de eerste steen gelegd voor een achthoekig steenen kerkgebouw op het Kerkplein, dat op 5 Juli 1835 werd ingewijd in tegenwoordigheid van prins Hendrik, die als jeugdig zeeofficier eene reis naar de koloniën volbracht. Het voor die kerk bestemde orgel was door schipbreuk verloren gegaan, doch werd in 1846 vervangen door 
een nieuw. En dit laatste werd in 1908 nog eens verwisseld voor een beter instrument. De kerk bekwam in 1902 'n soort van filiale door de stichting van het bedehuis Annetta op 's Landsgrond Boniface. 't Had de bestemming om te voorzien in de geestelijke behoeften van buitenleden der Herv. gemeente, die te ver van de hoofdplaats woonden, o.a. van de boeren-kolonisten uit den omtrek.

In de koloniën Essequebo en Berbice had men te kampen met dezelfde moeite om geschikte predikanten te vinden, dezelfde strubbelingen en dezelfde perioden van stilstand in het geestelijk werk als in Suriname. In het eerste gewest kwam reeds in 1688, als eerste predikant in het fort Kijkoveral, Rudolphus Heynens. Na hem traden op Jodocus Bate, Johannes van Golsbergen (die als planter in de kolonie bleef) en, tusschen de jaren 1719 en 1724, Zacharias Hofman. Van hen werd weinig goeds gezegd, zij werden beschreven als onverdraagzaam, aanmatigend of twistzoekend, of ook met recht ontevreden wanneer de planters, die den toeslag van 8 à $f 900$ op het karige salaris van $f 400$ moesten leveren, in de uitkeering daarvan nalatig bleven.

Als een sieraad van zijn stand werd daarentegen geroemd Hubertus Grevenbroek, die in 1730 het predikambt in Essequebo aanvaardde. Hij stond te boek als een belangeloos man, vroom, eenvoudig en vredelievend van aard, die gedurende 31 jaren de kolonie ten zegen verstrekte. Hij werd dan ook zeer gewaardeerd en herhaaldelijk, wanneer hij gelijk zijne voorgangers naar Nederland wilde terugkeeren, werd hem door bewindhebbers dringend verzocht om op zijn post te blijven. In den regel werd kerkdienst gehouden in het fort Zeelandia op het Vlaggen-eiland (later Fort-eiland genaamd) waar zich een steenen kerkje en ook de pastorie bevond. Voorts nam hij den dienst waar in het kerkje op den post Ampa, tegenover de samenvloeiing van Essequebo en Mazarouni, doch, gelijk hij in een zijner brieven vermeldde, preekte hij daar nagenoeg voor stoelen en banken. Ook bezocht hij sommige plantages, waar eenige prijs werd gesteld op kerkelijk bezoek. Ds. Grevenbroek was algemeen be- 
mind, in 't bijzonder bevriend met den directeur-generaal Storm van 's-Gravesande en de schoonvader van den secretaris Adriaan Spoors. Zulke familie-betrekkingen en zulke vriendschapsbanden bewogen hem in de kolonie te blijven, telkens wanneer bewindhebbers daarvoor bij hem aandrongen; doch eindelijk werd hem in 1761 op zijn herhaald verzoek, wegens hoogen leeftijd en wankele gezondheid, zijn emeritaat verleend salvo honore et emolumentis (met behoud van titel en ambtsvoordeelen).

Hij werd opgevolgd door Isaac Lingius, die eveneens een reeks van jaren in Essequebo doorbracht, en wien werd opgedragen om tweemaal 's jaars te Demarary „den heiligen dienst en het uytdeelen der Bondzeegelen te gaan verrigten". De kolonisten aldaar woonden nl. te ver van het fort Zeelandia om daar de godsdienstoefening bij te wonen; reeds in 1753 hadden de Engelsche planters onder hen van de Kamer Zeeland vergunning bekomen om zich te bedienen van een Engelschen voorlezer, die van Saba afkomstig was. Het duurde tot 1766 alvorens voor Demarary de eerste geregelde predikant werd aangesteld in den persoon van Hermanus Lingius, waarschijnlijk een broeder van Isaac Lingius. Nog omstreeks het jaar 1850 werd in het fort Zeelandia nu en dan godsdienstoefening gehouden door den laatsten Ned. Herv. predikant in Britsch Guiana, ds. G. Drost, die echter op de hoofdplaats Georgetown woonde.

(Slot volgt). 